\title{
Awareness of Cervical Cancer Risk Factors, Screening Practices and Attitudes among Nurses in a Primary Health Care Setting of Morocco: A Cross-Sectional Study
}

Najdi $\mathrm{A}^{* 1,2}$, Benaicha $\mathrm{N}^{2}$, El Fakir $\mathrm{S}^{2}$, Tachfouti $\mathrm{N}^{2}$, Berraho $\mathrm{M}^{2}$, Khazraji YC ${ }^{3}$, Belakhal ${ }^{4}$, Abousselham $L^{5}$, Bekkali $R^{3}$ and Nejjari $C^{2,6}$

${ }^{1}$ School of Medicine of Tangier, Morocco

${ }^{2}$ Laboratory of Epidemiology, Clinical Research and Community Health, School of Medicine of Fez, Morocco

${ }^{3}$ Lalla Salma Foundation for Cancer Prevention and Treatment, Rabat, Morocco

${ }^{4}$ Direction de lépidémiologie et de Lutte contre les maladies, Ministry of Health of Morocco, Morocco

${ }^{5}$ Directorate of Population, Ministry of Health of Morocco, Morocco

${ }^{6}$ University Mohammed VI of Health Sciences, Morocco

*Corresponding author: Najdi A, School of Medicine of Tangier, Morocco and Laboratory of Epidemiology, Clinical Research and Community Health, School of Medicine of Fez, Morocco, E-mail: najdi.adil2011@gmail. com

Citation: Najdi A, Benaicha N, El Fakir S, Tachfouti N, Berraho M, et al. (2016) Awareness of Cervical Cancer Risk Factors, Screening Practices and Attitudes among Nurses in a Primary Health Care Setting of Morocco: A Cross-Sectional Study. J Cancer Sci Clin Oncol 3(2): 203. doi: 10.15744/2394-6520.3.203

Received Date: May 17, 2016 Accepted Date: September 09, 2016 Published Date: September 12, 2016

\begin{abstract}
The effectiveness of the cervical cancer screening activities depends on physicians and nurses' level of awareness and their adherence to the program.

Aim: To characterize nurse's awareness, attitude and practice on cervical cancer screening in Morocco.

Method: A national cross sectional study conducted on July 2011 in a representative sample of nurses carrying out in Moroccan health care facilities. Five Moroccan regions were selected and 22 centers were included with a total of 306 nurses. A self-administered questionnaire was used to collect data on Socio demographic characteristics, Awareness about cervical cancer's risk factors, HPV's vaccination, and attitude regarding cervical cancer screening using the VIA test.

Result: A total of 306 nurses were included in the survey, the mean age was 45,15 $\pm 10,66$ years, the majority of them (95, 5\%) were females and carrying out in Urban health care facilities (83,4\%). When we asked nurses about their daily screening activities, $90 \%$ of them admitted they provide occasionally tests for cervical cancer screening for their patients but not regularly and not for all eligible patients. Univariate analysis of the data showed that nurses who work in rural areas $(p<0,02)$, who had less seniority in the public service $(p<0,05)$ and who were younger $(p<0,04)$, were less likely to perform cervical cancer screening in order to meet the targeted program's objectives. After adjustment on confounding factors, working in the rural area remained the only associated factor with low screening practice among nurses $(\mathrm{OR}=2,9 ; \mathrm{p}<0,02)$.

Conclusion: This study showed certain weaknesses regarding the functioning of the early detection program for cervical cancer at the primary health care level; mainly it shown the non-adherence of nurses at the rural area.

Keywords: Nurses; Cervical Cancer; Early detection; Morocco
\end{abstract}

\section{Introduction}

Globally, cervical cancer is one of the most common cancers in women, with an estimate of 528000 new cases and 266000 death in 2012 (IARC, GLOBOCAN 2008). According to the some report, about $87 \%$ of these cases occur in developing and developed countries. Mortality rates are substantially lower than incidence with a ratio of mortality to incidence to $52 \%$.

Morocco has the highest mortality cervical cancer rates in Northern Africa. Around 10 million Moroccan women 15 y-older are at risk of developing cervical cancer [1]. According to Casablanca 2005 - 2007 registry, cervical cancer is the second female cancer after breast cancer with $12.8 \%$ and a standardized incidence estimated at 15 per 100000 female. An extrapolation at national level shows that each year; there will be approximately 2000 new cases of cervical cancer in Morocco [2]. 
Since early detection predicts better prognosis, one of the most effective ways of preventing and controlling cervical cancer is regular screening and early diagnosis. In developing countries only 5\% of the cases are detected at the preclinical stages [3]. Indeed, in Morocco, the diagnosis of cervical cancer is predominantly made at advanced stages, and according to the FIGO classification, only $17.2 \%$ of patients were identified as being in early stages of cervical cancer (stage 0 in $0.5 \%$ and $\mathrm{I}$ in $16.7 \%$ ) and $82.8 \%$ were presented in intermediate to advanced stages: stage II in $43.7 \%$, stage III in $31.8 \%$, and stage IV in $6.3 \%$ [ 4 ].

A national program of early detection for cervical cancer was recently introduced in Morocco. This program aim to establish and to sustain the systematic screening of the women at risk in the primary health care structures. Health professionals practicing at this level of care system constitute the first line contact with the target screening population program. In addition, they are currently regarded as gatekeepers to and coordinators of cancer prevention activities [5]. Such that the effectiveness of the cervical cancer screening activities is directly dependent on physicians and nurses level of awareness and their adherence to the program.

To increase nurses' awareness of the importance of cervical cancer screening, we must understand what nurses know and do not know about cervical cancer and screening methods for. In addition, we should know how they perceive the problem and how they behave towards cervical cancer and early detection, as well as the barriers to and the predictors of the practice of early-detection methods. In our knowledge, no research has yet been done in this field in Morocco.

\section{Objectives}

- To describe awareness of cervical cancer risk factors among nurses in Moroccan primary health care sitting.

- To characterize nurse's attitude and practice on cervical cancer screening.

- Deduct membership adherence of nurses in the cervical cancer screening program.

\section{Methods}

\section{Study design}

A national cross sectional study conducted in July 2011 on a representative sample of nurses carrying out in Moroccan health care facilities.

\section{Sampling}

The target population was all nurses carrying out in the area covered by the program, i.e. five Moroccan regions. A sample size calculation was done based on the following parameters: an $80 \%$ statistical power, a 95\% confidence level and an expected proportion of perfect awareness about of $50 \%$.

A first degree cluster sampling was used with stratification on rural-urban residential area; for each region, a predetermined number of health care facility centers were selected at random and all nurses working in the selected centers were interviewed.

For each following regions: Fez, Meknes, Rabat and Errachidia, two urban and one rural center were selected. For Casablanca region five districts were selected including in sum 8 urban centers and 2 rural centers. In total, 22 centers were included with a total of 306 nurses who completed the questionnaire. The response rate was about $99 \%$.

\section{Data collection}

A self-administered questionnaire was used to collect data outside working time. The data collected was as follows:

- Socio demographic characteristics: age, sex, length of exercise as a nurse.

- Awareness about cervical cancer's risk factors: nurses were asked about 26 factors.

- Awareness about HPV and HPV's vaccination.

- Awareness and attitude regarding cervical cancer screening and especially the VIA test.

\section{Statistical analysis}

Data were entered on Excel and analyzed on Epi-Info software. Quantitative variables are presented as means \pm standard deviation and qualitative variables as percentages.

Univariate analysis was carried out using Student-test for comparing means and Chi-square test to compare percentages. A multivariate analysis using binary logistic regression was performed for adjusting on confounder factors.

\section{Ethical issues}

This study has been presented to the local ethics committee of University Hospital Hassan II of Fez who agreed it. An informed consent formula has been sent to every potential participant explaining the aim of the study and clearly the fact that this was on a voluntary basis and that they can quit at any time without penalty. Questionnaires, upon receipt, have been assigned a unique number and at any time during the analysis of the study no person had been cited. This point was also clearly stated in the informed consent so that the potential participant was not reluctant to give confidential information. 


\section{Results}

\section{Nurses Characteristics and involvement in cancer prevention}

A total of 306 nurses were included in the survey, the mean age was $45.15 \pm 10$, 66 years, the majority of them (95.5\%) were females and carrying out in urban health care facilities (83.4\%). Given that the study was conducted in the "Training area" most nurses $(91.6 \%)$ has already received training on cervical cancer screening. Time length of the training was an average of $8.42 \pm 6.32$ months at the moment of survey completion (Table 1).

\begin{tabular}{|c|c|c|c|}
\hline \multicolumn{2}{|c|}{ Characteristics } & N & \multicolumn{2}{c|}{$\%$} \\
\hline Age (n=283) & & \multicolumn{2}{c|}{$45.15 \pm 10.66$} \\
\hline \multirow{2}{*}{ Sex } & F & 278 & 95.5 \\
\cline { 2 - 4 } & M & 13 & 4.5 \\
\hline \multirow{2}{*}{ Exercising area } & Morocco & 291 & 100 \\
\cline { 2 - 4 } & Abroad & 0 & 0 \\
\hline Seniority in the public service & Urban & 241 & 83.4 \\
\cline { 2 - 4 } & Rural & 48 & 16.6 \\
\hline Seniority in current position & & $21.47 \pm 11.11$ \\
\hline $\begin{array}{c}\text { Subjects who received training } \\
\text { sessions in cancer prevention }\end{array}$ & & $12.27 \pm 9.37$ \\
\hline
\end{tabular}

Table 1: Demographic and professional nurses characteristics $(n=306)$

Awareness about cervical cancer's risk factors (Table 2)

\begin{tabular}{|c|c|c|c|c|}
\hline Items & $\begin{array}{l}\text { Risk Factor } \\
\text { (\%) }\end{array}$ & $\begin{array}{l}\text { Protecting } \\
\text { factor (\%) }\end{array}$ & $\begin{array}{c}\text { No association } \\
(\%)\end{array}$ & $\begin{array}{c}\text { Don't know } \\
(\%)\end{array}$ \\
\hline Early age at first menstruation & 38.7 & 1.1 & 45.7 & 14.5 \\
\hline Multiparity & 61.4 & 5.7 & 25.7 & 7.1 \\
\hline Early age at first pregnancy & 59.0 & 3.9 & 29.8 & 6.4 \\
\hline tardy age at last pregnancy & 31.8 & 2.9 & 49.3 & 16.1 \\
\hline Number of spontaneous abortion & 55.2 & 2.1 & 30.6 & 12.1 \\
\hline Number of caused abortion & 78.0 & 1.4 & 14.9 & 5.7 \\
\hline Early menopause & 29.6 & 8.0 & 43.4 & 19.0 \\
\hline obesity & 40.4 & 0.4 & 46.6 & 12.6 \\
\hline Overweight & 37.0 & 1.4 & 49.3 & 12.3 \\
\hline Physical inactivity & 37.9 & 2.3 & 42.5 & 17.2 \\
\hline Family history of cervical cancer & 72.1 & 1.0 & 24.4 & 2.4 \\
\hline Family history of cancer & 62.7 & 1.4 & 26.9 & 9.0 \\
\hline Oral contraceptive use & 53.6 & 5.0 & 35.4 & 6.1 \\
\hline Injectable contraception & 42.3 & 6.6 & 40.9 & 10.2 \\
\hline Tobacco & 71.4 & 1.8 & 20.4 & 6.4 \\
\hline Sexually transmitted infections & 96.5 & 0.7 & 2.8 & 00 \\
\hline Herpes genitalis & 82.9 & 0.7 & 9.6 & 6.8 \\
\hline Genital condyloma & 81.9 & 1.1 & 6.4 & 10.6 \\
\hline Early age at Sexual activity start & 74.9 & 1.1 & 15.9 & 8.1 \\
\hline Multiple sexual partners & 94.4 & 0.7 & 2.8 & 2.1 \\
\hline $\begin{array}{l}\text { Sexual intercourse during } \\
\text { menstruation }\end{array}$ & 64.9 & 1.1 & 12.5 & 21.5 \\
\hline immunodeficiency & 86.6 & 1.8 & 6.1 & 5.4 \\
\hline stress & 54.8 & 2.5 & 34.4 & 8.2 \\
\hline Antioxidant intake & 26.3 & 24.5 & 22.3 & 27.0 \\
\hline Animal protein consumption & 52.9 & 4.3 & 28.8 & 14.0 \\
\hline
\end{tabular}

Table 2: Awareness of cervical cancer risk factors among nurses $(n=306)$ 
We asked several risk factors whether or not in relation to cervical cancer. Of the 306 nurses interviewed, majority (between 75\% and $95 \%$ of them) believed that history of sexually transmitted infections (STI) and risky sexual behaviors were the main risk factor for cervical cancer.

Moreover, $87 \%$ reported immunodeficiency, $71.4 \%$ reported smoking, $72 \%$ reported family history of cervical cancer, $54 \%$ reported oral contraception use and $61 \%$ reported multiparity were risk factors for cervical cancer.

Regarding others factors, for instance age at the first and the last pregnancy, early age at first menstruation and early menopause, stress, animal protein consumption, obesity, overweight and physical inactivity, nurse's responses varied mainly between risk factors and no association.

\section{Awareness about Human papilloma virus (HPV) $(n=268)$}

Among all responding nurses, 239 (89\%) knew the HPV infection and recognized its role as risk factor for cervical cancer. In addition, $90 \%$ of them believed HPV is sexually transmitted and $64.5 \%$ asserted its association with condyloma and genital warts. On the other hand, $75 \%$ thought that the HPV is transmittable by both genders, $65 \%$ were aware about the HPV vaccine but only $41 \%$ believed that the condom use cannot allow a total protection against the HPV transmission (Table 3).

\begin{tabular}{|c|c|c|c|}
\hline Items & Affirmative (\%) & Negative (\%) & Don't know (\%) \\
\hline Already heard about HPV & 89.2 & 10.8 & ----------- \\
\hline $\begin{array}{l}\text { HPV infection is a risk factor } \\
\text { for cervical cancer }\end{array}$ & 91.6 & 1.9 & 6.5 \\
\hline $\begin{array}{l}\text { HPV is associated with } \\
\text { condyloma and genital warts }\end{array}$ & 64.5 & 17.9 & 17.5 \\
\hline HPV infection is immunizing & 24.4 & 48.4 & 27.2 \\
\hline HPV is sexually transmitted & 90.0 & 3.1 & 6.9 \\
\hline $\begin{array}{l}\text { HPV is transmitted through } \\
\text { body fluids (saliva, sperm...) }\end{array}$ & 56.2 & 27.9 & 15.9 \\
\hline $\begin{array}{l}\text { HPV may be transmitted by } \\
\text { both genders }\end{array}$ & 74.8 & 16.9 & 8.3 \\
\hline $\begin{array}{l}\text { The condom provides a total } \\
\text { protection }\end{array}$ & 55.6 & 40.7 & 3.7 \\
\hline $\begin{array}{c}\text { Awareness of the existence of } \\
\text { the HPV vaccine }\end{array}$ & 64.5 & 35.5 & \\
\hline
\end{tabular}

Table 3: Awareness about human papilloma virus (HPV) among nurses ( $\mathrm{n}=268)$

\section{Screening practice and attitudes $(n=269)$}

When we asked nurses about their daily screening activities, $90 \%$ of them admitted they provide occasionally tests for cervical cancer screening for their patients. But not regularly and not for all eligible patients. When we questioned them, the main reasons mentioned were the refusal of patients to be screened by a male examiner (notice of 84 nurses), On the other hand, 104 nurses argued they have too much patients and therefore they have not enough time for screening. Thirdly, 102 nurses complained about the lake of adequate spaces for the examination. Univariate analysis of the data (Table 4 and 5) showed that nurses who work in rural areas $(\mathrm{p}<0.02)$, who had less seniority in the public service $(\mathrm{p}<0.05)$ and who were younger $(\mathrm{p}<0.04)$, were less likely to perform cervical cancer screening in order to meet the targeted program's objectives. After adjustment on confounding factors, working in the rural area remained the only associated factor with low screening practice among nurses $(\mathrm{OR}=2.9 ; \mathrm{p}<0.02)$.

Regarding the visual inspection with acetic acid (VIA), among 242 responding nurses $97.5 \%$ had already read about this technique.

\begin{tabular}{|c|c|c|}
\hline Items & Affirmative (\%) & Negative (\%) \\
\hline $\begin{array}{c}\text { Do you offer any exams for cervical } \\
\text { cancer screening to your patients? }\end{array}$ & 90.3 & 9.7 \\
\hline You aware of the VIA? & 97.5 & 2.5 \\
\hline
\end{tabular}

Table 4: Daily screening practice and attitudes among nurses $(n=269)$

\begin{tabular}{|c|c|c|c|c|c|c|c|}
\hline \multicolumn{2}{|c|}{ Variables } & \multicolumn{2}{|c|}{$\begin{array}{l}\text { Systematic Screening } \\
\text { practice (\% or mean) }\end{array}$} & \multirow[b]{2}{*}{$\mathbf{p}$} & \multirow[b]{2}{*}{$\mathrm{ORa}^{*}$} & \multirow[b]{2}{*}{$95 \% \mathrm{CI}$} & \multirow[b]{2}{*}{$\mathbf{P}$} \\
\hline & & Yes & No & & & & \\
\hline \multirow{2}{*}{$\operatorname{Sex}(n=261)$} & Male & 100 & 00 & 0.61 & --- & & --- \\
\hline & Female & 90 & 10 & & & & \\
\hline \multirow{2}{*}{$\begin{array}{l}\text { Exercising area } \\
\qquad(n=257)\end{array}$} & Urban & 92.4 & 7.6 & $<0.02$ & 1 & $1.2-7.0$ & $<0.02$ \\
\hline & Rural & 80.9 & 19.1 & & 2.9 & & \\
\hline
\end{tabular}




\begin{tabular}{|c|c|c|c|c|c|c|}
\hline \multirow[t]{2}{*}{ Variables } & \multicolumn{2}{|c|}{$\begin{array}{l}\text { Systematic Screening } \\
\text { practice ( } \% \text { or mean) }\end{array}$} & \multirow[b]{2}{*}{$\mathbf{p}$} & \multirow[b]{2}{*}{$\mathrm{ORa}^{*}$} & \multirow[b]{2}{*}{$95 \% \mathrm{CI}$} & \multirow[b]{2}{*}{$\mathbf{P}$} \\
\hline & Yes & No & & & & \\
\hline $\begin{array}{l}\text { Seniority in the public service } \\
\text { (years) }(n=255)\end{array}$ & $21.7 \pm 11.3$ & $17.4 \pm 10.0$ & $<0.05$ & --- & & --- \\
\hline $\begin{array}{l}\text { Seniority in current position } \\
\text { (years) }(n=239)\end{array}$ & $12.5 \pm 9.7$ & $9.3 \pm 7.6$ & 0.14 & --- & & --- \\
\hline Age (years) $(n=252)$ & $45.4 \pm 10.6$ & $40.9 \pm 11.8$ & $<0.04$ & --- & & --- \\
\hline
\end{tabular}

${ }^{*}$ Adjusted OR

Table 5: Screening practice's associated factors after univariate and multivariate analysis

\section{Discussion}

This study forms part of the evaluation program for early detection of Breast and cervical cancers in Morocco. The program contained trainings for cervical abnormalities screening and cervical cancer risk factors which were supplied to the nurses in primary health care facility. The current research seeks to assess the level of their present knowledge and their practical attitudes regarding screening for cervical cancer.

Two main findings were highlighted by this study. The first is related to the knowledge of nurses which is found globally acceptable although gaps persist concerning knowledge on certain risk factors. The second observation concerns the attitudes and the practice of screening in daily activities by nurses in the areas covered by the program. Actually we found that this practice is low and unable to meet the program objectives in terms of quantity.

Globally, nurses in this study had adequate knowledge about cervical cancer risk factors, other studies in Uganda, Turkey, Nigeria and Tanzania didn't shown the some findings [7-10]. This can be explained by the fact that our survey was conducted in the "training area" where most nurses have already taken training about cervical cancer in order to implement the early detection program. Although Time length of the training was an average of $8.42 \pm 6,32$ months at the moment of survey completion it can be deduced that training has had a good impact on nurses' knowledge. However, we found some gaps in nurse's knowledge regarding the prevention of the Human papilloma virus (HPV) transmission, in fact, about $60 \%$ of nurses believed that condom can allow a total protection against the HPV transmission. Given that the use of condoms is not a replacement for other methods of prevention such as the vaccination, it is necessary to carry out more sensitization about this issue in order to redress and to rectify nurses' awareness.

Nurses have a crucial role in health education and in rising awareness of the target population regarding the HPV vaccine. Indeed, studies have shown that attitudes of teenage girls toward the HPV vaccines are directly dependent on their level of knowledge on the HPV infection either in developed countries or in developing countries $[11,12]$. So, in order that nurses can play their role fully and effectively as health educators, their knowledge must be improved and constantly updated. This, in conjunction with strengthening their role as opinion leaders in their respective communities [13].

The first contact for women who are eligible for cervical cancer screening with the health institution is usually with the nurse and hence the onus is on the paramedical worker who handles the eligible women to offer screening or refer her to a reference center where specialized test can be done [14]. Studies showed that screening for precancerous cervical lesions using visual inspection with acetic acid is a simple, low cost and efficient alternative to cytologic testing in low-resource areas moreover, other studies from other African low income countries (Sudan-Mozambique) showed that VIA is a feasible and acceptable cervical cancer screening method in a primary health care setting [15-17]. Morocco implemented since 2010 a systematic IVA based screening for cervical cancer in Primary health care facility. Training sessions were organized for all nurses in order to familiarize and to motivate them to use VIA for all eligible women. However, we found in our study that attitudes and practices among nurses towards cervical cancer screening were negative, most nurses admitted that they didn't provide regularly tests and not for all eligible patients. They self-explained this by a several reasons, mainly, the refusal of eligible women, the lack of examination spaces dues to the overcrowding of primary health care facilities and the lack of time to do screening. All these aspects must be considered by the program managers and a multiple approach should be envisaged.

More deeply, this survey revealed that nurses in rural area are less likely to practice systematic cervical screening for targeted women. This fact can be explained by two main reasons: The first one is the overwhelming charge of work for personal paramedical in rural area. Actually, the ratio of personal paramedical by habitant is much lesser in rural area than in urban area (www.sante. gov.ma). The second explanation to this difference is that nurses in rural area are usually less experienced than their peers in urban area, as the new graduates nurses are mostly affected in the rural area which are less desirable than the urban area. This can be different from other countries. Actually, Tran, et al. (2011) made a comparative study among rural and urban female health care practitioners in Korea regarding KAP and screening for cervical cancer. The authors didn't found major differences between rural and urban respondents regarding their KAP [6]. 
There are certain limitations related to the questions which are mainly recognition and some recall type. Both the recall and recognition questions have limitations. Recall underestimates awareness because it is limited by memory, while recognition overestimates awareness because participants find it easy to guess. Secondly, the order of the questions may have an impact on the findings. However, in most situations it is not pragmatically feasible to randomize the order in which the questions are asked and moreover, the questionnaire was tested by the pilot study. However, this study was very relevant to evaluate the cervical cancer screening program and also useful to emphasize the deficiencies of our health system.

\section{Conclusion}

This study reveals that the utilization of cervical cancer screening services among nurses in Morocco is still low despite the implementation of a cancer plan. Strategies that encourage cervical cancer utilization by health workers must be advocated. It can be recommended that the program responsible organize more seminars and training for health personnel especially nurses, these nurses must also be motivated, there work must be recognized and awarded if excellent.

\section{Questionnaire}

\section{References}

1. LSFC. National Cancer Prevention and Control Plan in Morocco 2010-2019.

2. Registre des cancers de la grande région de Casablanca 2005-2007.

3. WHO. Comprehensive cervical cancer control: a guide to essential practice 2006.

4. Plan National de Prévention et de Contrôle de Cancer Vol 3. 2009.

5. Lee MM, Lee F, Stewart S, Mcphee S (1999) Cancer screening practices among primary care physicians serving Chinese Americans in San Francisco. West J Med 170: 148-55.

6. Tran NT, Choe SI, Taylor R, Ko WS, Pyo HS, et al. (2011) Knowledge, attitude and practice (KAP) concerning cervical cancer and screening among rural and urban women in six provinces of the Democratic People's Republic of Korea. Asian Pac J Cancer Prev 12: 3029-33.

7. Mutyaba T, Mmiro FA, Weiderpass E (2006) Knowledge, attitudes and practices on cervical cancer screening among the medical workers of Mulago Hospital, Uganda. BMC Med Educ 6: 13.

8. Yaren A, Ozkilinc G, Guler A, Oztop I (2008) Awareness of breast and cervical cancer risk factors and screening behaviours among nurses in rural region of Turkey. Eur J Cancer Care 17: 278-84.

9. Ayinde OA, Omigbodun AO (2003) Knowledge, attitude and practices related to prevention of cancer of the cervix among female health workers in Ibadan. J Obstet Gynaecol 23: 59-62.

10. Urasa M, Darj E (2011) Knowledge of cervical cancer and screening practices of nurses at a regional hospital in Tanzania. Afr Health Sci 11 : 48-57.

11. Navalpakam A, Dany M, Hajj Hussein I (2016) Behavioral Perceptions of Oakland University Female College Students towards Human Papillomavirus Vaccination. PLoS One 11: e0155955.

12. Dany M, Chidiac A, Nassar AH (2015) Human papillomavirus vaccination: assessing knowledge, attitudes, and intentions of college female students in Lebanon, a developing country. Vaccine 33: 1001-7.

13. Rosen BL, DiClemente R, Shepard AL, Wilson KL, Fehr SK (2016) Factors associated with school nurses' HPV vaccine attitudes for school-aged youth. Psychol Health Med 12: 1-11.

14. Singh E, Seth S, Rani V, Srivastava DK (2012) Awareness of cervical cancer screening among nursing staff in a tertiary institution of rural India. J Gynecol Oncol 23: 141-6.

15. Sauvaget C, Fayette JM, Muwonge R, Wesley R, Sankaranarayanan R (2011) Accuracy of visual inspection with acetic acid for cervical cancer screening. Int J Gynaecol Obstet 113: 14-24.

16. Ibrahim A, Rasch V, Pukkala E, Aro AR (2011) Cervical cancer risk factors and feasibility of visual inspection with acetic acid screening in Sudan. Int J Womens Health 3: 117-22.

17. Moon TD, Silva-Matos C, Cordoso A, Baptista AJ, Sidat M, et al. (2012) Implementation of cervical cancer screening using visual inspection with acetic acid in rural Mozambique: successes and challenges using HIV care and treatment programme investments in Zambézia Province. J Int AIDS Soc 15: 17406.

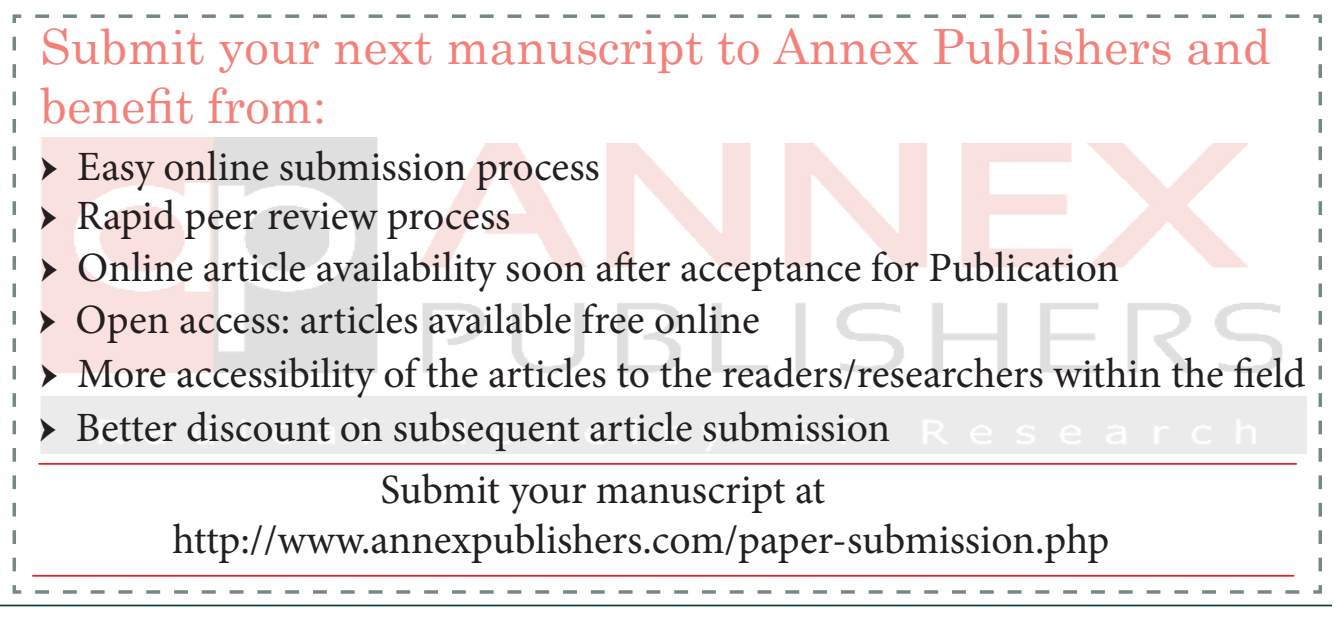

